Please refer to the following:

Farkas J, Jármai K

Volume and cost minimization of a tubular truss with displacement-constraint

ADVANCES IN STRUCTURAL ENGINEERING 15:(10) pp. 1729-1737. (2012)

\title{
Volume and cost minimization of a tubular truss with displacement-constraint
}

\author{
J. Farkas ${ }^{1} \&$ K. Jármai ${ }^{2}$ \\ University of Miskolc, H-3515 Miskolc, Egyetemváros, Hungary \\ Ialtfar@uni-miskolc.hu_2altjar@uni-miskolc.hu
}

\begin{abstract}
The minimum volume and cost of a simply supported planar truss with $\mathrm{N}$-type bracing is optimized. The lower chord of the truss is horizontal, but the symmetric upper chord parts are non-parallel and their inclination angle as well as the cross-sectional area of CHS (circular hollow section) rods are optimized. For the calculation of required cross-sectional area of compression struts closed formulae are used as a good approximation of Eurocode 3 buckling curve. A special method is developed for the minimum volume design considering the deflection constraint. In the case of a strong displacement constraint the cross-sectional areas required for the allowed deflection are larger than those required for stress and buckling constraints. The cost function includes the cost of material, cutting and grinding of CHS strut ends, assembly, welding and painting. Special mathematical methods are used to find the optima in the case of a numerical problem.
\end{abstract}

Keywords: tubular truss, structural optimization, overall buckling, displacement constraint, minimum cost design

\section{INTRODUCTION}


Tubular trusses are applied in many load-carrying structures such as roofs, bridges, offshore platforms, towers etc. A literature survey of the optimum design of trusses is given in Section 2.

The aim of the present study is to show the minimum volume and cost optima of a truss and solve the optimum design problem subject to a strong displacement constraint. In the case of stress constraints the tension rods are designed for yield stress by using a safety factor for loading and the compression rods are designed for overall buckling. In the case of a strong displacement constraint the required cross-sectional areas are larger than those required for stress constraints.

In the optimum design process of a truss the optimal value of the cross-sectional areas of struts and the geometric characteristics of the truss are sought which minimize an objective function and fulfil the design and fabrication constraints. The objective function can be the volume (weight) or cost, the design constraints are the limitation of stress and displacement, the fabrication constraints ease the manufacturing (welding) process.

In the case of an active displacement constraint a special method is developed to calculate the required cross-sectional areas and the truss geometry. This method is derived in details in Section 3 .

It is shown that the non-parallel chords are more economic than the beam with parallel chords. Thus, in our case the angle of the upper chord (unknowns $h_{9}$ and $h_{13}$ in Figure 1) is optimized.

Another problem is the grouping of rods having the same cross-sectional area. The design of all the rods having different cross-sectional areas can cause difficulties in fabrication, but the design of all the rods with the same cross-sectional area would be uneconomic. Thus, the economy depends on grouping of rods. In our case four groups are used. 
For the minimization of the structural volume or cost, minimization of the cross-sectional areas of rods is needed. The cross-sectional area of compression rods cannot be calculated from the Eurocode 3 buckling formulae. Therefore approximate formulae of Japan Road Association are used. Stress and buckling constraints are calculated using factored forces, whilst the deflection is calculated with forces without a safety factor.

To obtain comparable optima the required cross-sectional areas are not rounded to available profiles and the most economic $\delta=D / t=50$ slenderness (diameter/thickness) of CHS is used. The limitation of the angle between CHS struts (minimum $30^{\circ}$ ) is taken into account as a fabrication constraint. Another fabrication constraint is that the diameters of the chords should be larger than those of verticals and diagonals of the bracing.

The effect of self mass is neglected in this comparative study.

\section{SURVEY OF SELECTED LITERATURE}

In order to illustrate the literature of the optimum design of trusses, the characteristics of some articles are summarized in Table 1.

Table 1. Literature survey of selected journal articles about the optimization of trusses Abbreviations: AISC American Institute of Steel Construction, CHS Circular Hollow Section, AASHTO American Assoc. of State and Highway Transportation Officials, EC3 Eurocode 3 (EN 1993-1-1: 1992), W - American wide flange beam, PSO particle swarm optimizer, ACO ant colony strategy, HS harmony search, MINLP mixed-integer nonlinear programming, alum - aluminium

\begin{tabular}{lllllll}
\hline Author(s) & Examples & $\begin{array}{l}\text { Math. } \\
\text { Method }\end{array}$ & $\begin{array}{l}\text { Mate- } \\
\text { rial }\end{array}$ & $\begin{array}{l}\text { Buckling } \\
\text { calculation }\end{array}$ & $\begin{array}{l}\text { Cross- } \\
\text { section }\end{array}$ & $\begin{array}{l}\text { Constraint } \\
\text { Gil (2001) }\end{array}$ \\
& $\begin{array}{l}\text { non-parallel } \\
\text { chords }\end{array}$ & $\begin{array}{l}\text { conjugates } \\
\text { gradient }\end{array}$ & steel & EC3 & & $\begin{array}{l}\text { stress and } \\
\text { geometrical }\end{array}$ \\
\hline
\end{tabular}




\begin{tabular}{|c|c|c|c|c|c|c|}
\hline $\begin{array}{l}\text { Tong } \\
(2001)\end{array}$ & 10-,25-bar & $\begin{array}{l}\text { combina- } \\
\text { torial }\end{array}$ & alum. & & & $\begin{array}{l}\text { stress and } \\
\text { fundamental } \\
\text { frequency }\end{array}$ \\
\hline $\begin{array}{l}\text { Makris } \\
(2002)\end{array}$ & $\begin{array}{l}\text { 3-,10-,25-,60- } \\
\text { and 132-bar }\end{array}$ & $\begin{array}{l}\text { strain- } \\
\text { energy- } \\
\text { density }\end{array}$ & alum. & no buckling & & displacement \\
\hline $\begin{array}{l}\text { Hasancebi } \\
(2002)\end{array}$ & $\begin{array}{l}\text { 224-bar } 3 \mathrm{D} \\
\text { pyramid, } \\
\text { simply } \\
\text { supported }\end{array}$ & $\begin{array}{l}\text { simulated } \\
\text { annealing }\end{array}$ & steel & AISC & $\begin{array}{l}\text { CHS, } \\
\text { W- } \\
\text { section }\end{array}$ & $\begin{array}{l}\text { layout } \\
\text { optimization }\end{array}$ \\
\hline $\begin{array}{l}\text { Kripakaran } \\
(2007)\end{array}$ & 10-,18-,21-bar & $\begin{array}{l}\text { new } \\
\text { algorithm }\end{array}$ & $\begin{array}{l}\text { steel, } \\
\text { alum. }\end{array}$ & $\begin{array}{l}\text { AASHTO, } \\
\text { Euler }\end{array}$ & CHS & $\begin{array}{l}\text { minimum } \\
\text { cost }\end{array}$ \\
\hline $\begin{array}{l}\text { Lamberti } \\
\text { (2008) }\end{array}$ & $\begin{array}{l}\text { 18-bar } \\
\text { cantilever, 25- } \\
\text { bar 3D, 45-,72- } \\
\text { and 200-bar }\end{array}$ & $\begin{array}{l}\text { simulated } \\
\text { annealing }\end{array}$ & $\begin{array}{l}\text { steel, } \\
\text { alum. }\end{array}$ & Euler & & $\begin{array}{l}\text { stress, nodal } \\
\text { displacement }\end{array}$ \\
\hline $\begin{array}{l}\text { Silih } \\
(2008)\end{array}$ & $\begin{array}{l}\text { non-parallel } \\
\text { chords }\end{array}$ & MINLP & steel & EC3 & CHS & $\begin{array}{l}\text { minimum } \\
\text { mass or cost }\end{array}$ \\
\hline $\begin{array}{l}\text { Kaveh } \\
(2009)\end{array}$ & $\begin{array}{l}10-, 25-, 120- \\
200-, \text { and } 244- \\
\text { bar trans- } \\
\text { mission tower }\end{array}$ & $\begin{array}{l}\text { PSO, } \\
\text { ACO,HS }\end{array}$ & $\begin{array}{l}\text { steel, } \\
\text { alum. }\end{array}$ & AISC & & $\begin{array}{l}\text { stress, nodal } \\
\text { displacements }\end{array}$ \\
\hline $\begin{array}{l}\text { Jármai } \\
\text { (2004) }\end{array}$ & $\begin{array}{l}\text { Simply } \\
\text { supported, } \\
\text { parallel chords, } \\
5,8 \text { spacing }\end{array}$ & $\begin{array}{l}\text { Leap-frog, } \\
\text { dynamic- } \\
\text { Q }\end{array}$ & Steel & EC3 & CHS & $\begin{array}{l}\text { optimum } \\
\text { height, effect } \\
\text { of loads, min. } \\
\text { volume }\end{array}$ \\
\hline
\end{tabular}

Remarks:

(1) In trusses the compression members should be designed against overall buckling. The use of Euler-formula gives unsafe design, since it does not take into account the effect of initial imperfections and residual stresses. Therefore buckling formulae of Eurocode 3 or another up-to-date improved buckling formulae should be used. 
(2) The type of the investigated cross section should be given, since it has been shown (Farkas \& Jármai 1997) that the cross-sectional form affects the optima significantly.

\section{MINIMUM VOLUME DESIGN OF THE TUBULAR TRUSS WITH NON-PARALLEL}

\section{CHORDS}

Relatively simple formulae can be derived for trusses to minimize the structural volume and fulfil a displacement constraint.

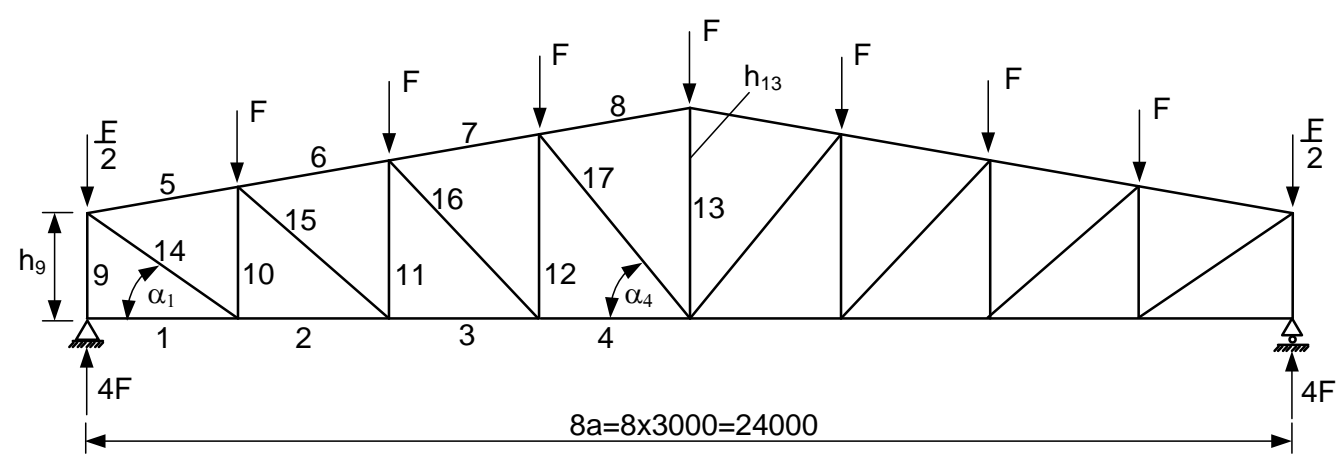

Figure 1. The simply supported truss with non-parallel chords

The truss rods are divided into $n$-groups having the same cross-sectional areas $\left(A_{i}\right)$, so

$$
A_{i}=\mu_{i} A, \quad i=1 \ldots n,
$$

where $\mu_{i}$ are multipliers and the displacement constraint is given by

$$
w=\frac{1}{E A} \sum_{i} \frac{S_{i} s_{i} L_{i}}{\mu_{i}} \leq w_{0}
$$

where $E$ is the elastic modulus, $S_{i}$ is the rod force, $s_{i}$ is the rod force from the unit force acting at the midspan, $L_{i}$ is the rod length, $w_{o}$ is the admissible deflection. 
From Eqn (2) one obtains

$$
A \geq \frac{1}{E w_{0}} \sum_{i} \frac{S_{i} s_{i} L_{i}}{\mu_{i}}
$$

The structural volume is calculated as

$$
V=\sum_{i} A_{i} L_{i}=\frac{1}{E w_{0}} \sum_{i} \mu_{i} L_{i} \sum_{i} \frac{S_{i} s_{i} L_{i}}{\mu_{i}}=\frac{v_{1} v_{2}}{E w_{0}},
$$

where $v_{i}$ parameters are

$$
v_{1}=\sum_{i} \mu_{i} L_{i}, \quad v_{2}=\sum_{i} \frac{S_{i} s_{i} L_{i}}{\mu_{i}}
$$

In the minimum volume design the truss geometry is sought, which minimizes

$$
V_{1}=v_{1} v_{2}
$$

In the case of the simply supported truss shown in Figure 1 the spacing is constant, the nonparallel upper chord is determined by variable heights $h_{9}$ and $h_{13}$. The truss is subject to a set of vertical static forces $F$ acting on the upper nodes. The displacement of the central lower node is prescribed. It is supposed that all the truss nodes are restrained against transverse deformation.

The variables to be optimized are the heights $h_{9}$ and $h_{13}$ as well as the cross sectional areas of rods $\left(A\right.$ and $\left.\mu_{i}\right)$.

The calculations show that, in the case of a strong displacement constraint the necessary rod cross-sectional areas are so large that the stress constraints on tension and overall buckling are fulfilled. In spite of this fact these constraints should be checked.

To facilitate the welding of nodes for tubular trusses a geometric fabrication constraint should be considered that the minimal angle between rods should be equal or greater than $30^{\circ}$, in our case (Figure 1) 


$$
\tan \alpha_{1}=\frac{h_{9}}{a} \geq \tan 30^{\circ}
$$

where $a$ is the distance between columns, from which

$$
h_{9} \geq \operatorname{atan} 30^{\circ}=1732 \mathrm{~mm}
$$

and

$$
\tan \alpha_{4} \leq 60^{\circ}=\frac{\pi}{3}
$$

In our case these constraints are always active.

The rod forces and lengths $\left(S_{i}, s_{i}, L_{i}\right)$ are expressed in function of $h_{9}$ and the inclination angle of the upper chords $\alpha$.

$$
\tan \alpha=\frac{h_{13}-h_{9}}{4 a}, \cos \alpha=\frac{1}{\sqrt{(\tan \alpha)^{2}+1}}, \sin \alpha=\sqrt{1-(\cos \alpha)^{2}} .
$$

The formulae for $S_{i}, s_{i}$ and $L_{i}$ are given in Tables 2, 3, 4 and 5.

Table 2. Characteristics of rods in the lower chord

\begin{tabular}{cccc}
\hline$i$ & $S_{i}$ & $s_{i}$ & $L_{i}$ \\
\hline 1 & 0 & 0 & $A$ \\
\hline 2 & $3.5 F a / h_{10}$ & $0.5 a / h_{10}$ & $A$ \\
\hline 3 & $6 F a / h_{11}$ & $a / h_{11}$ & $A$ \\
\hline 4 & $7.5 F a / h_{12}$ & $1.5 a / h_{12}$ & $A$ \\
\hline
\end{tabular}


Table 3. Characteristics of rods in the upper chord

\begin{tabular}{cccc}
\hline$I$ & $S_{i}$ & $s_{i}$ & $L_{i}$ \\
\hline 5 & $\frac{3.5 F a}{h_{10} \cos \alpha}$ & $\frac{0.5 a}{h_{10} \cos \alpha}$ & $\frac{a}{\cos \alpha}$ \\
\hline 6 & $\frac{6 F a}{h_{11} \cos \alpha}$ & $\frac{a}{h_{11} \cos \alpha}$ & $\frac{a}{\cos \alpha}$ \\
\hline 7 & $\frac{7.5 F a}{h_{12} \cos \alpha}$ & $\frac{1.5 a}{h_{12} \cos \alpha}$ & $\frac{a}{\cos \alpha}$ \\
\hline 8 & $\frac{8 F a}{h_{13} \cos \alpha}$ & $\frac{2 a}{h_{13} \cos \alpha}$ & $\frac{a}{\cos \alpha}$ \\
\hline
\end{tabular}

Table 4. Characteristics of verticals

\begin{tabular}{cccc}
\hline$i$ & $S_{i}$ & $s_{i}$ & $L_{i}$ \\
\hline 9 & $4 F$ & 0.5 & $h_{9}$ \\
\hline 10 & $-3.5 F+S_{5} \sin \alpha$ & $-0.5+s_{5} \sin \alpha$ & $h_{10}=h_{9}+a \tan \alpha$ \\
\hline 11 & $-2.5 F+S_{6} \sin \alpha$ & $-0.5+s_{6} \sin \alpha$ & $h_{11}=h_{9}+2 a \tan \alpha$ \\
\hline 12 & $-1.5 F+S_{7} \sin \alpha$ & $-0.5+s_{7} \sin \alpha$ & $h_{12}=h_{9}+3 a \tan \alpha$ \\
\hline 13 & $-F+2 S_{8} \sin \alpha$ & $2 s_{8} \sin \alpha$ & $h_{13}$ \\
\hline
\end{tabular}


Table 5. Characteristics of diagonals

\begin{tabular}{cccc}
\hline$i$ & $S_{i}$ & $s_{i}$ & $L_{i}$ \\
\hline 14 & $S_{5} L_{14} \cos \alpha / a$ & $s_{5} L_{14} \cos \alpha / a$ & $\sqrt{h_{9}^{2}+a^{2}}$ \\
& & & \\
\hline 15 & $\left(2.5 F-S_{6} \sin \alpha\right) L_{15} / h_{10}$ & $\left(0.5-s_{6} \sin \alpha\right) L_{15} / h_{10}$ & $\sqrt{h_{10}^{2}+a^{2}}$ \\
\hline 16 & $\left(1.5 F-S_{7} \sin \alpha\right) L_{16} / h_{11}$ & $\left(0.5-s_{7} \sin \alpha\right) L_{16} / h_{11}$ & $\sqrt{h_{11}^{2}+a^{2}}$ \\
\hline 17 & $\left(0.5 F-S_{8} \sin \alpha\right) L_{17} / h_{12}$ & $\left(0.5-s_{8} \sin \alpha\right) L_{17} / h_{12}$ & $\sqrt{h_{12}^{2}+a^{2}}$ \\
& & & \\
\hline
\end{tabular}

The rods are divided into four groups having the same cross-section): lower chord $(1,2,3,4)$, upper chord $(5,6,7,8)$, verticals $(9,10,11,12,13)$ and diagonals $(14,15,16,17)$.

In order to facilitate the fabrication, the lower and upper chords have the same cross-section $\left(\mu_{1}=\mu_{2}=1\right)$ and the optimal values of $\mu_{3}$ (multiplier for verticals) and $\mu_{4}$ (multiplier for diagonals) are sought, which should be smaller than $\mu_{1}$.

The components of $V_{1}=v_{1} v_{2}$ to be minimized are as follows.

$$
\begin{gathered}
v_{1}=8\left(a+L_{7}\right)+2 \mu_{3} \sum_{i=9}^{12} h_{i}+\mu_{3} h_{13}+2 \mu_{4} \sum_{i=14}^{17} L_{i}, \\
v_{2}=2 a \sum_{i=2}^{4} S_{i} S_{i}+2 L_{7} \sum_{i=5}^{8} S_{i} S_{i}+\frac{2}{\mu_{3}} \sum_{i=9}^{12} S_{i} s_{i} h_{i}+\frac{S_{13} S_{13} h_{13}}{\mu_{3}}+\frac{2}{\mu_{4}} \sum_{i=14}^{17} S_{i} S_{i} L_{i},
\end{gathered}
$$


With the optimum values of $h_{9}, h_{13}, \mu_{3}$ and $\mu_{4}$

$$
A_{1}=A_{2}=\frac{v_{2 o p t}}{E w_{a d m}}, A_{3}=\mu_{3 o p t} A_{1}, A_{4}=\mu_{4 o p t} A_{1} .
$$

The minimum structural volume is

$$
V_{\text {min }}=v_{1} A_{1} \text {. }
$$

For a circular hollow section (CHS of diameter $D$ and thickness $t$ )

$$
A=\pi D t=\pi D^{2} / \delta, \delta=D / t
$$

from which

$$
D=\sqrt{\frac{A \delta}{\pi}}, t=\frac{D}{\delta} .
$$

In the design we should use the maximum value of $\delta$, but it is limited to 50 (Wardenier et al. 1991). In the case of available CHS profiles according to (EN 10210-2. 2006) $\delta$ is varied between 10-50. In order to obtain realistic optima in all cases the optimum $\delta=50$ is used.

\section{CHECK OF THE COMPRESSION RODS FOR OVERALL BUCKLING}

For checking the overall buckling, the approximate formulae of the Japan Road Association (JRA) (Hasegawa et al. 1985) can be used instead of EC3 curve (b). In this case closed formulae can be given for cross-sectional sizes.

$$
\begin{gathered}
N / A \leq \chi f_{y}, \\
\chi=1 \text { for } \quad 0 \leq \bar{\lambda} \leq 0.2, \\
\chi=1.109-0.545 \bar{\lambda} \quad \text { for } 0.2 \leq \bar{\lambda} \leq 1, \\
\chi=\frac{1}{0.773+\bar{\lambda}^{2}} \quad \text { for } \quad \bar{\lambda} \geq 1,
\end{gathered}
$$


where $f_{y}$ is the yield stress, $N$ is the compression force, $\chi$ is the overall buckling parameter. Introducing the symbol

$$
\vartheta=100 D / L
$$

and using $\bar{\lambda}=c / \vartheta$ the closed formulae are as follows.

For $0.2 \vartheta \leq c \leq \vartheta$

$$
\vartheta=0.24572 c\left[1+\sqrt{1+\frac{14.93475 v}{c^{2}}}\right],
$$

and for $\vartheta \leq c$

$$
\vartheta=\left\{0.3865 v\left[1+\sqrt{1+\frac{6.69424 c^{2}}{v}}\right]\right\}^{1 / 2},
$$

for CHS

$$
c=\frac{100 K \sqrt{8}}{\lambda_{E}}, \quad v=\frac{10^{4} S}{L^{2}} \cdot \frac{\delta}{\pi f_{y}},
$$

where the limiting value of $\delta=D / t=50$ is used

$$
D=\frac{\vartheta L}{100}
$$

In the case of very long struts with small compressive force, the limitation of the strut slenderness can be governing. From the limitation of

$$
\lambda=K_{R} L / r \leq \lambda_{\max }
$$

the required radius of gyration is

$$
r \geq K_{R} L / \lambda_{\max }
$$

According to (BS 5400 1983) $\lambda_{\max }=180$.

$K_{R}$ is the strut end restraint factor, for chords $K_{R}=0.9$, for verticals and diagonals $K_{R}=0.75$ (Rondal et al. 1992). 
For the check of overall buckling the following constraint should be fulfilled for all compression rods

$$
A_{i} \geq \frac{\pi D_{i}}{\delta}
$$

where $A_{i}$ is the optimum cross-sectional area for displacement constraint and $D_{i}$ is the required diameter from overall buckling calculation.

\section{THE COST FUNCTION}

The cost function contains the cost of material, cutting and grinding of CHS strut ends, assembly, welding and painting.

The cost of material is given by

$$
K_{M}=k_{M} \rho V_{2},
$$

where an average specific cost of $k_{M}=1.0 \$ / \mathrm{kg}$ is considered, $\rho=7.85 \times 10^{-6} \mathrm{~kg} / \mathrm{mm}^{3}$ for steel. $V_{2}$ is the actual structural volume (see Eqn (35)).

The cost of cutting and grinding of CHS strut ends is calculated with a formula proposed by Glijnis (Farkas \& Jármai 2003).

$$
K_{C G}(\$)=k_{F} \Theta_{C G} \frac{2.5 \pi D}{(350-2 t) 0.3 \sin \alpha},
$$

where $k_{F}=1.0 \$ / \mathrm{min}$ is the specific fabrication cost, $\Theta_{C G}=3$ is a factor for work complexity, $350 \mathrm{~mm} / \mathrm{min}$ is the cutting speed, 0.3 is the efficiency factor, diameter $D$ and thickness $t$ are in $\mathrm{mm}, \alpha$ is the inclination angle of diagonal braces.

In our case for verticals

$$
K_{C G}=\Theta_{C G} 2.5 \pi 9 D_{3} \frac{1+\frac{1}{\cos \alpha}}{\left(350-2 t_{3}\right) 0.3} .
$$

For diagonals at the lower strut ends 


$$
K_{C G 1}=\Theta_{C G} 2.5 \pi 2 D_{4} \frac{\sum_{i=1}^{4} \frac{1}{\cos \alpha_{i}}}{\left(350-2 t_{4}\right) 0.3}
$$

where

$$
\tan \alpha_{1}=h_{9} / a, \tan \alpha_{2}=h_{10} / a, \tan \alpha_{3}=h_{11} / a, \tan \alpha_{.4}=h_{12} / a .
$$

For diagonals at the upper strut ends

$$
K_{C G 2}=\Theta_{C G} 2.5 \pi 2 D_{4} \frac{\sum_{i=1}^{4} \frac{1}{\cos \beta_{i}}}{\left(350-2 t_{4}\right) 0.3},
$$

where

$$
\beta_{i}=90^{0}-\alpha-\alpha_{i}, \mathrm{i}=1,2,3,4
$$

The general formula for the welding cost is as follows (Farkas \& Jármai 1997, 2003, 2008).

$$
K_{w}=k_{w}\left(C_{1} \Theta \sqrt{\kappa \rho V}+1.3 \sum_{i} C_{w i} a_{w i}^{n} C_{p i} L_{w i}\right),
$$

where $k_{w}[\$ / \mathrm{min}]$ is the welding cost factor, $C_{l}$ is the factor for the assembly usually taken as $C_{1}=1 \mathrm{~min} / \mathrm{kg}^{0.5}, \Theta$ is the factor expressing the complexity of assembly, the first member calculates the time of the assembly, $\kappa$ is the number of structural parts to be assembled, $\rho V$ is the mass of the assembled structure. The second member estimates the time of welding, $C_{w}$ and $n$ are the constants given for the specified welding technology and weld type.

Furthermore $C_{p i}$ is the factor for the welding position (download 1, vertical 2, overhead 3), $L_{\mathrm{w}}$ is the weld length, the multiplier 1.3 takes into account the additional welding times (deslagging, chipping, changing the electrode, etc.).

In our case $k_{w}=1.0 \$ / \mathrm{min}, \Theta=3$,

the cost of assembly and welding using SMAW (shielded metal arc welding) fillet welds is given by for verticals

$$
K_{W}=k_{W}\left[\Theta \sqrt{21 \rho V_{2}}+1.3 \times 0.7889 \times 10^{-3} \times 9 \pi D_{3}\left(1+\frac{1}{\cos \alpha}\right) t_{3}^{2}\right] \text {, }
$$




$$
V_{2}=8 a A_{1}+8 L_{7} A_{2}+2 A_{3} \sum_{i=9}^{12} h_{i}+A_{3} h_{13}+2 A_{4} \sum_{i=14}^{17} L_{i} .
$$

For diagonals at the lower strut ends

$$
K_{W 1}=1.3 \times 0.7889 \times 10^{-3} \times 2 \pi D_{4} t_{4}^{2} \sum_{i=1}^{4} \frac{1}{\cos \alpha_{i}} .
$$

For diagonals at the upper strut ends

$$
K_{W 1}=1.3 \times 0.7889 \times 10^{-3} \times 2 \pi D_{4} t_{4}^{2} \sum_{i=1}^{4} \frac{1}{\cos \beta_{i}} .
$$

The cost of painting is calculated as

$$
K_{P}=k_{P} S_{P}, k_{P}=28.8 \times 10^{-6} \$ / \mathrm{mm}^{2} .
$$

The superficies to be painted is

$$
S_{P}=8 a \pi D_{1}+8 L_{7} \pi D_{2}+2 \pi D_{3} \sum_{i=9}^{12} h_{i}+\pi D_{3} h_{13}+2 \pi D_{4} \sum_{i=14}^{17} L_{i} .
$$

The total cost is given by

$$
K=K_{M}+K_{C G}+K_{C G 1}+K_{C G 2}+K_{W}+K_{w 1}+K_{w 2}+K_{P} .
$$

\section{NUMERICAL DATA}

Loads for displacement calculation (without safety factor) $F=120000 \mathrm{~N}$, for stress and buckling constraints $F_{0}=1.5 F=180000 \mathrm{~N}$ (safety factor of 1.5). Yield stress of steel $f_{y}=355$ MPa, elastic modulus $E=2.1 \times 10^{5} \mathrm{MPa}$, span length $L=24 \mathrm{~m}$, allowable displacement at the middle of the span $w_{0}=32 \mathrm{~mm}=L / 750$.

\section{THE OPTIMIZATION PROCESS}


Calculate the optimum values of $h_{9}, h_{13}, \mu_{3}$ and $\mu_{4}$ to obtain $V_{\min }$ or $K_{\min }$ and fulfil the constraints on displacement, on minimum angle $\alpha_{1}$ [Eqn. (8)], on maximum angle $\alpha_{4}$ [Eqn. (9)] as well as on stress and overall buckling.

The ranges of unknowns are as follows: $1732<h_{9}<5000 \mathrm{~mm}, 4000<h_{13}<8000 \mathrm{~mm}$ and $h_{9}<h_{13}, 0.5<\mu_{3}<1,0.5<\mu_{4}<1$.

In the case of minimum volume design Eqns. (13) and (14) give the results and Eqn. (25) should be fulfilled. In the case of minimum cost Eqn. (40) should be minimized, for which Eqns. (11), (12), (13), (16) and (35) should be used.

\section{RESULTS OF THE OPTIMIZATION}

The fabrication constraints [Eqn. (7) and (8)] determine the optimal pair of unknowns $h_{9}$ and $h_{13}$ as follows: for a given $h_{9}$ a value of $h_{13}$ smaller than $h_{13 \mathrm{opt}}$ gives larger $v_{1} v_{2}$, larger does not fulfil the fabrication constraint Eqn. (8). Table 6 shows the $\max h_{13}$ in function of $h_{9}$.

Table 6. Maximum $h_{13}$ values in function of $h_{9}$. Values in $\mathrm{mm}$

\begin{tabular}{llllllll}
\hline$h_{9}$ & 1750 & 1850 & 1950 & 2000 & 2100 & 2200 & 2300 \\
\hline$h_{13 o p t}$ & 6340 & 6310 & 6280 & 6260 & 6220 & 6190 & 6160
\end{tabular}

Furthermore the calculations show that the best value for $\mu_{3}$ and $\mu_{4}$ is 0.6 , since the value of 0.5 gives cross-sections which do not fulfil the buckling constraints. Thus, the remaining unknown $h_{9}$ can be optimized using the MathCAD program. Table 7 gives the volume and cost in function of $h_{9}$. The optimum $h_{9}$ minimizes thee product $v_{1} v_{2}$ (fulfilling the deflection constraint) and also $V$ and $K$.

Table 7. Volume and cost in the function of $h_{9} . h$ in mm. Optima are marked with bold letters 


\begin{tabular}{|c|c|c|c|c|}
\hline$h_{9}$ & $h_{13}$ & $v_{1} v_{2} \times 10^{-15}$ & $V x 10^{-8} \mathrm{~mm}^{3}$ & $K \$$ \\
\hline 1750 & 6390 & 2.331 & 3.469 & 7854 \\
\hline 1850 & 6310 & 2.324 & 3.459 & 7830 \\
\hline $\mathbf{1 9 5 0}$ & $\mathbf{6 2 8 0}$ & $\mathbf{2 . 3 2 1}$ & $\mathbf{3 . 4 5 4}$ & $\mathbf{7 8 2 5}$ \\
\hline 2000 & 6260 & 2.322 & 3.456 & 7829 \\
\hline 2100 & 6220 & 2.327 & 3.463 & 7843 \\
\hline
\end{tabular}

Table 7 shows that the following optima are determined: in the case of $\mu_{3}=\mu_{4}=0.6, h_{9 \mathrm{opt}}=$ $1950, h_{13 \mathrm{opt}}=6280, v_{1} v_{2 \mathrm{~min}}=2.321 \times 10^{15}, V_{\min }=3.454 \times 10^{8} \mathrm{~mm}^{3}, K_{\min }=7825 \$, A_{1}=A_{2}=$ $3708, A_{3}=A_{4}=2225 \mathrm{~mm}^{2}$. Table 7 shows that the sensitivity of $V$ and $K$ is small.

The cross-sectional areas required for stress and buckling constraints are as follows: $A_{1}=A_{2}$ $=2195, A_{3}=2084, A_{4}=2094 \mathrm{~mm}^{2}$. It can be seen that the cross-sectional areas determined for a strong displacement constraint are larger than those required for stress or buckling constraints.

In addition the calculation results for $\mu_{3}=0.7$ and $\mu_{4}=0.5$ are given.

Table 8. Results in the case of $\mu_{3}=0.7$ and $\mu_{4}=0.5$. Optimum is marked by bold letters

\begin{tabular}{|c|c|c|}
\hline$h_{9}$ & $h_{13}$ & $v_{1} v_{2} \times 10^{-15}$ \\
\hline 1750 & 6390 & 2.335 \\
\hline 1850 & 6310 & 2.329 \\
\hline $\mathbf{1 9 5 0}$ & $\mathbf{6 2 8 0}$ & $\mathbf{2 . 3 2 6}$ \\
\hline 2000 & 6260 & 2.328 \\
\hline 2100 & 6220 & 2.334 \\
\hline
\end{tabular}


Another optimum values for $h_{9}=1950 \mathrm{~mm}: A_{1}=A_{2}=3728, A_{3}=2610, A_{4}=1864 \mathrm{~mm}^{2} . \mathrm{V}=$ $3.462 \times 10^{8} \mathrm{~mm}^{3}, K=7818 \$$. Since $A_{4}=2094 \mathrm{~mm}^{2}$ is necessary for buckling constraint, the value of $\mu_{4}=0.5$ is too small and $\mu_{4}=0.6$ should be used.

For comparison the optimum data for the truss of parallel chords: $h_{9 o p t}=h_{13 o p t}=5000 \mathrm{~mm}$, $V_{\min }=5.852 \times 10^{8} \mathrm{~mm}^{3} . K_{\min }=11350 \$$. It can be seen that the truss of non-parallel chords is much more economic than the truss of parallel chords.

\section{CHECK OF STRENGTH OF A TUBULAR JOINT}

After the optimization the optimal cross-sections should be replaced by available profiles according to EN 10291-2 and the joints should be checked for strength according to new IIW rules (Static design 2009). To illustrate this procedure a tubular joint of the truss optimized for strength is shown in Figure 2.

The related rod forces are as follows: $S_{3}=787.4 \mathrm{kN}$ (tension), $S_{12}=11.1 \mathrm{kN}$ (tension), $S_{15}=$ $233.4 \mathrm{kN}$ (tension), governing for diagonals, also for rod 16, for which $S_{16}=13820 \mathrm{~N}$ compression.

The available CHS profiles for the optimized truss are as follows: chords: Ø273.0x5 mm, verticals and diagonals: $\varnothing 139.7 \times 6 \mathrm{~mm}$.

According to Figure 2 the joint is designed an overlap K-joint, with the eccentricity of $e=$ $0.25 \times 273=68 \mathrm{~mm}$, the overlap is $O v=100 q / p=100 \times 34.3 / 161.6=21.2 \%$. 


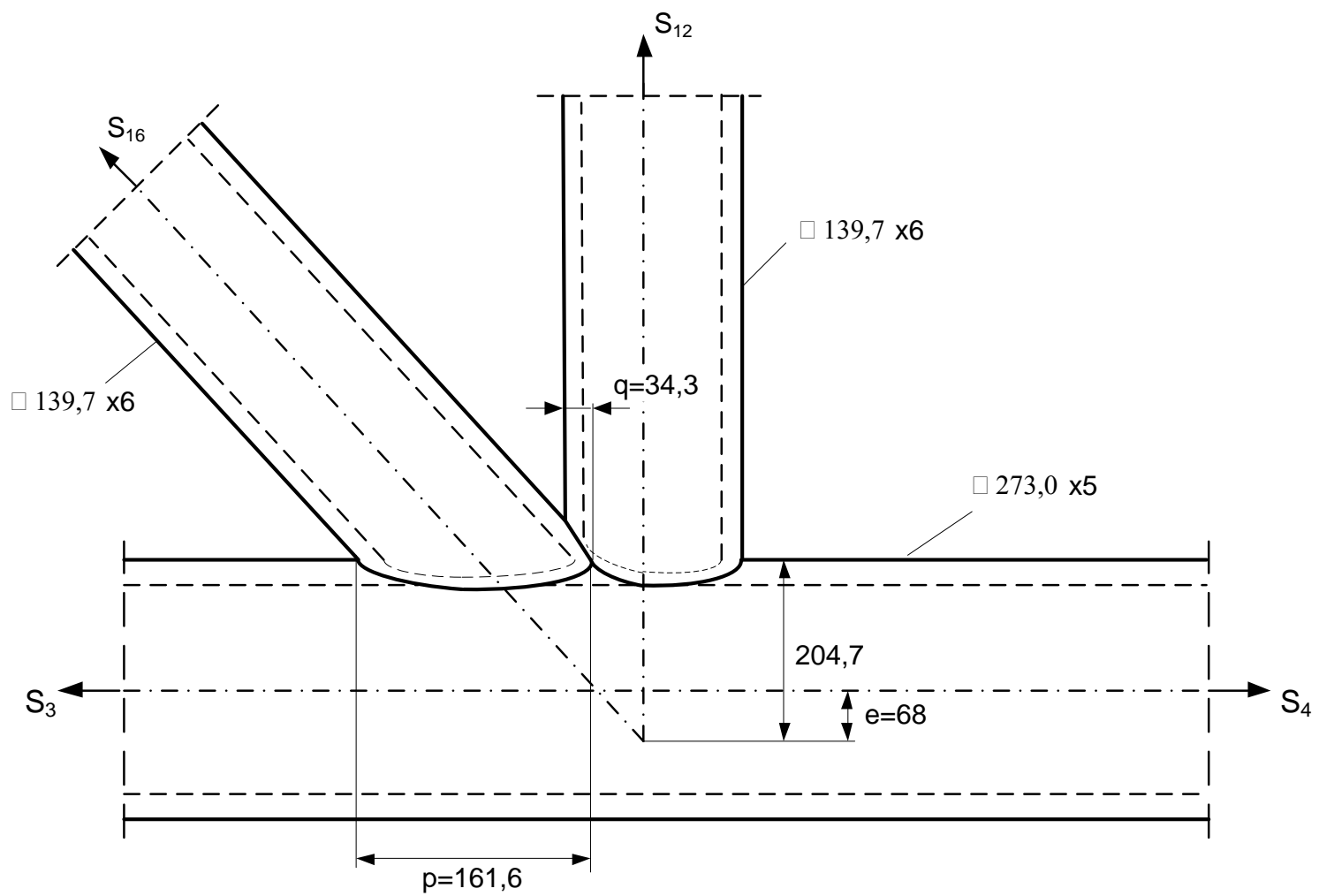

Figure 2. The overlapped tubular joint

(a) Check of local yielding of overlapping brace

$$
\begin{gathered}
N^{*}=f_{y} t_{i} L_{b . e f f}, \\
L_{b . e f f}=\frac{\pi}{4}\left(2 d_{i}+d_{e i}+d_{e . o v}-4 t_{i}\right), \\
d_{e i}=\frac{12}{d_{0} / t_{0}} \frac{t_{0}}{t_{i}} d_{i} \leq d_{i} .
\end{gathered}
$$

Indices: for overlapping brace $\mathrm{i}$, for overlapped brace $\mathrm{j}$

$$
d_{e . o v}=\frac{12}{d_{j} / t_{j}} \frac{t_{j}}{t_{i}} d_{i} \leq d_{i}
$$

In our case $d_{0}=273, d_{i}=d_{j}=139.7, t_{i}=t_{j}=6, t_{0}=5$

$$
d_{e i}=25.6, d_{e o v}=72, L_{b . e f f}=277.2 .
$$




$$
N^{*}=355 \times 6 \times 277.2=5900533>233400 \mathrm{~N}, \mathrm{OK} .
$$

(b) Check of local chord member yielding

$$
\left(\frac{N_{0}}{N_{p l .0}}\right)^{1.7} \leq 1, \quad N_{\mathrm{pl} .0} \geq N_{0}, \quad N_{\mathrm{pl} .0}=A f_{y},
$$

$N_{p l .0}=3781 \times 355=1342255>787400 \mathrm{~N}, \mathrm{OK}$.

(c) Check of brace shear

$N_{i} \cos \theta_{i}+N_{j} \cos \theta_{j} \leq N_{S} *$

$N_{S} *=\frac{\pi}{4}\left(0.58 f_{u i} \frac{\frac{100-O v}{100} 2 d_{i}+d_{e i}}{\sin \theta_{i}} t_{i}+0.58 f_{u i} \frac{2 d_{j}+d_{e j}}{\sin \theta_{j}} t_{j}\right)$.

In our case $O v=21.2, f_{u i}=510, d_{e i}=d_{e j}=25.6, d_{i}=d_{j}=139.7, t_{i}=t_{j}=6$,

$S_{15} \cos \theta_{j}=116700<N_{S} *=833513 \mathrm{~N}, \mathrm{OK}$.

\section{CONCLUSIONS}

The optimization problem to be solved is the following: find the optimal geometry and crosssectional areas of rods which minimize the structural volume or cost for a simply supported tubular truss with non-parallel chords for a strong displacement constraint.

For the solution of this problem a developed calculation method is used. Besides the displacement constraint the rods are checked for tension stress and overall buckling. It is shown that, in the case of a strong displacement constraint the cross-sectional areas are larger than those required for constraints on stress and buckling.

The fabrication (welding) constraints on minimal angle between tubular rods $\left(30^{\circ}\right)$ have been also active. In the calculation of overall buckling the Eurocode 3 formulae are approximated 
by formulae of Japan Road Association enabling the explicit expression of the necessary cross-sectional area.

Special formulae are used for the cost calculation. The cost function expresses the cost of material, cutting and grinding of the tubular (CHS) rod ends, assembly, welding and painting. It is shown that, in this case, the structural optima for minimum volume and minimum cost are the same.

Check of strength of a tubular joint shows that the chords and braces of available CHS profiles fulfil the requirements.

\section{ACKNOWLEDGEMENTS}

The authors gratefully acknowledge the support of the Hungarian Scientific Research Fund under the OTKA 75678 project number. The project was also supported by the TÁMOP 4.2.1.B-10/1/KONV-2010-0001 Increasing the quality of higher education through the development of research-development and innovation program at the University of Miskolc.

\section{REFERENCES}

BS 5400 (1983) Steel, concrete and composite bridges. Part 3: Code of practice for design of steel bridges. British Standard Institution, London.

EN 1993-1-1: (2005) Design of steel structures. Part 1.1. General rules and rules for buildings. European Committee for Standardization (CEN).

EN 10219-2: (2006) Cold formed circular hollow section profiles. European Committee for Standardization (CEN).

Farkas J., Jármai K. (1997) Analysis and optimum design of metal structures. Balkema, Rotterdam-Brookfield. 
Farkas J., Jármai K. (2003) Economic design of metal structures. Rotterdam, Millpress.

Farkas J., Jármai K. (2008) Design and optimization of metal structures. Chichester, UK, Horwood Publishing.

Gil L., Andreu A. (2001) Shape and cross-section optimization of a truss structure. Computers and Structures Vol. 79, pp. 681-689.

Hasancebi O., Erbatur F. (2002) Layout optimization of trusses using simulated annealing. Advances in Engineering Software Vol. 33, pp. 681-696.

Hasegawa A.,H., Abo et al. (1985) Optimum cross-sectional shapes of steel compression members with local buckling. Proc. JSCE Structural Engineering/ Earthquake Engineering, Vol. 2, pp. 121-129.

Jármai K., Snyman J.A., Farkas J. (2004) Application of novel constrained optimization algorithms to the minimum volume design of planar CHS trusses with parallel chords. Engineering Optimization, Vol. 36, No. 4, pp. 457-471.

Kaveh A., Talatahari S. (2009) Particle swarm optimizer, ant colony strategy and harmony search scheme hybridized for optimization of truss structures. Computers and Structures Vol. 87, pp. 267-283.

Kripakaran P., Gupta A., Baugh J.W.jr. (2007) A novel optimization approach for minimum cost design of trusses. Computers and Structures, Vol. 85, pp. 1782-1794.

Lamberti L. (2008) An efficient simulated annealing algorithm for design optimization of truss structures. Computers and Structures Vol. 86, pp. 1936-1953.

Makris P.A., Provatidis Ch.G. (2002) Weight minimization of displacement-constrained truss structures using a strain energy criterion. Computer Methods in Applied Mechanics and Engineering Vol. 191, pp. 2159-2177.

EN 10210-2: (2006) Hot finished structural hollow sections. European Committee for Standardization (CEN). 
Rondal J., Würker K-G. et al. (1992) Structural stability of hollow sections. Köln, TÜV Rheinland.

Static design procedure for welded hollow section joints. IIW Document XV-1329-09. International Institute of Welding, 2009.

Šilih S., Kravanja S. (2008) Topology, shape and standard sizing optimization of trusses using MINLP optimization approach. In: Design, Fabrication and Economy of Welded Structures. Internat. Conf. Proc. 2008. Miskolc, Hungary. Jármai,K., Farkas,J. (eds). Chichester, Horwood Publ. pp. 143-150.

Tong W.H., Liu G.R. (2001) An optimization procedure for truss structures with discrete variables and dynamic constraints. Computers and Structures Vol. 79, pp. 155-162.

Wardenier J., Kurobane Y. et al. (1991) Design guide for circular hollow section joints under predominantly static loading. Köln, TÜV Rheinland. 